\title{
Half-Life Volatility Measure of the Returns of Some Cryptocurrencies
}

\author{
Abonongo John ${ }^{1}$, Anuwoje Ida Logubayom ${ }^{1}$, Raymond Nero ${ }^{2}$ \\ ${ }^{1}$ Department of Statistics, Faculty of Mathematical Sciences, University for Development Studies, Tamale, Ghana \\ ${ }^{2}$ Department of Mathematics, College of Science, Kwame Nkrumah University of Science and Technology, Kumasi, Ghana \\ Email: *abonongojohn@gmail.com
}

How to cite this paper: John, A., Logubayom, A. I., \& Nero, R. (2019). Half-Life Volatility Measure of the Returns of Some Cryptocurrencies. Journal of Financial Risk Management, 8, 15-28. https://doi.org/10.4236/jfrm.2019.81002

Received: September 14, 2018

Accepted: March 10, 2019

Published: March 13, 2019

Copyright $\odot 2019$ by author(s) and Scientific Research Publishing Inc. This work is licensed under the Creative Commons Attribution International License (CC BY 4.0).

http://creativecommons.org/licenses/by/4.0/

\begin{abstract}
This paper explores the half-life volatility measure of three cryptocurrencies (Bitcoin, Litecoin and Ripple). Two GARCH family models were used (PGARCH $(1,1)$ and GARCH $(1,1))$ with the student-t distribution. It was realised that, the PGARCH $(1,1)$ was the most appropriate model. Therefore, it was used in determining the half-life of the three returns series. The results revealed that, the half-life was 3 days, 6 days and 4 days for Bitcoin, Litecoin and Ripple respectively. This shows that, the three coins have strong mean reversion and short half-life and that it takes the respective days for volatility in each of coin to return half way back without further volatility.
\end{abstract}

\section{Keywords}

Half-Life, Cryptocurrencies, Volatility, Mean Reversion, GARCH

\section{Introduction}

In recent years, a new type of currencies, a synthetic one, emerged. This new type of currency is named as "synthetic" because it is not the decision of a nation or state, nor represents any underlying asset or tangible wealth source. It appears as a new tradable asset resulting from a private agreement and facilitated by the anonymity of internet. Among this synthetic currencies, Bitcoin (BTC) emerges as the most important one, with a market capitalization of 17 billion, as of June 2018. There are other cryptocurrencies, based on block chain technology, such as Litecoin (LTC), Ethereum (ETH), and Ripple (XRP) among others. Cryptocurrency is an asset derived from mathematical cryptography; it is based on a new technology called the block chain (Bradbury, 2013; Ali et al., 2014). Its other fundamental characteristics are: being decentralised, and having a fixed total number of coins: 21 million, with more than 16 million already in circulation. 
One open question today is if cryptocurrencies are in fact, or may be considered as a currency. Until now, we cannot observe that cryptocurrencies fulfils the main properties of a standard currency. They are barely accepted as a medium of exchange (e.g. to buy some products online); it is not used as unit of account (there are no financial statements valued in any cryptocurrency), and we can hardly believe that, given the great swings in price, anyone can consider any cryptocurrency as a suitable option to store value. Given these characteristics, none of the cryptocurrencies could be considered as an ideal asset for speculative purposes. There are no underlying assets to relate their value to and there is an open platform to operate round the clock.

Most of the existing studies focused on Bitcoin returns. For example, Baur et al. (2017) show that Bitcoin returns are essentially uncorrelated with traditional asset classes such as stocks or bonds, which points to diversification possibilities. Others investigated the determinants of Bitcoin returns. The findings of Li Xin and Chong Alex Wang (2017), among others, suggest that measures of financial and macroeconomic activity are drivers of Bitcoin returns. Kristoufek Ladislav (2015) considered financial uncertainty, Bitcoin trading volume in Chinese Yuan and Google trends as potential drivers of Bitcoin returns. The inclusion of Google trends as some sort of proxy for sentiment or interest is fairly common within the literature (see, for example, Polasik et al. (2015)). A recurrent theme in the literature is the question to which asset class Bitcoin belongs, with many comparing it to gold; others to precious metals or to speculative assets (see, among others, Baur et al. (2017); or Bouri et al. (2017)). Some have classified Bitcoin as something in between a currency and a commodity (see, for example, Dehrberg Anne Haubo (2016)). For other recent contributions, see Cheah et al. (2018); Khuntia Sashikanta and J.K Paltanayak (2018); and Koutmos Dimimtrios (2018).

Some literatures try to model Bitcoin volatility. Among the first papers was Balcilar et al. (2017), who analysed the causal relation between trading volume and Bitcoin returns and volatility. They found that volume cannot help predict the volatility of Bitcoin returns. Dehrberg Anne Haubo (2016) explored Bitcoin volatility using GARCH models. The models estimated in Dehrberg Anne Haubo (2016) revealed Bitcoin has several similarities with both gold and the dollar. Bouri et al. (2017) found no evidence for asymmetry in the conditional volatility of Bitcoins when considering the post December 2013 period and investigate the relation between the VIX index and Bitcoin volatility. Al-Khazali et al. (2018) considered a model for daily Bitcoin returns and showed that, Bitcoin volatility tends to decrease in response to positive news about the US economy. Katsiampa Paraskevi (2017) explored the applicability of several ARCH-type specifications to model Bitcoin volatility and selected an AR-CGARCH model as the preferred specification. Although Katsiampa Paraskevi (2017) suggested that Bitcoin volatility consists of long and short-term components, he did not investigate the determinants of Bitcoin volatility. 
More recently, Conrad and Kleen (2018) used the GARCH-MIDAS model to extract the long and short term volatility component of cryptocurrencies. They considered measures of volatility and risk in the US stock market as well as a measure of global activity. It was realized that, S \& P 500 volatility had a negative and highly significant effect on long term Bitcoin volatility. They also found the, the S \& P 500 volatility risk premium had a significantly positive effect on long term Bitcoin volatility and that there is a positive association between Baltic dry index and long-term Bitcoin volatility. Salisu et al. (2018) exploited several condition heteroskedasticity models with various supported distributions in order to find the best distribution as well as the best GARCH-type model that could be used to model volatility of Bitcoin returns. They established that, pre-testing the residuals of the Bitcoin returns for the best distribution could help to identify the appropriate distribution when modelling with GARCH-type models regardless of the data frequency.

The purpose of this paper is to investigate the half-life volatility measure of some cryptocurrencies. This is to provide players on the cryptocurrency market with information pertaining to the half-life measure and volatility persistence of some of the cryptocurrencies so as to make informed choice on their investments.

\section{Material and Methods of Analysis}

\subsection{Source of Data}

This paper used secondary data of three cryptocurrencies (Bitcoin (BTC), Litecoin (LTC) and Ripple (XRP)) from the CoinMarketCap comprising the daily closing prices from the period $04 / 08 / 2013$ to $11 / 06 / 2018$, totalling 5319 observations.

\subsection{Methods of Data Analysis}

The daily closing prices were converted into compound returns given by;

$$
r_{t}=\log \left(\frac{p_{t}}{p_{t-1}}\right)
$$

where $r_{t}$ is the continuous compound returns at time $t, p_{t}$ is the current closing coin price at time $t$ and $p_{t-1}$ is the previous closing coin price.

\subsection{Volatility Modelling}

The error term of the GARCH-type model is fitted into the following distributions: Gaussian, Student's-t and Generalized Error.

For flexibility, the first lag is allowed in the relevant variables both in the mean and variance equations. An ARMA $(1,1)$ is the mean equation common to the GARCH-type models given by;

$$
r_{t}=\alpha+\beta r_{t-1}+\varepsilon_{t}+\theta \varepsilon_{t-1}
$$

where, $\beta \neq 0 ; \theta \neq 0$ and $\varepsilon_{t}=\sigma_{t} e_{t}$ and $\sigma_{t}$ is the conditional standard deviation. 
The respective variance equation of the latter varies for the two GARCH-type models (GARCH $(1,1)$ and PGARCH $(1,1)$ ) but with a common lag combination $(1,1)$ for the ARCH and GARCH components respectively.

The GARCH-type models considered are:

1) The Generalized ARCH (GARCH) Model-GARCH $(1,1)$;

$$
\sigma_{t}^{2}=\alpha_{o}+\alpha_{1} \varepsilon_{t-1}^{2}+\beta_{1} \sigma_{t-1}^{2}
$$

where, $\alpha_{o}$ is a constants, $\sigma_{t}^{2}$ is the squared volatility, $\alpha_{1}$ is the coefficient of the lagged squared residuals, $\varepsilon_{t-1}^{2}$ is the lagged squared residual from the mean equation and $\beta_{1}$ is the coefficient for the GARCH component (lagged conditional variance). Also, $\alpha_{o}>0, \alpha_{1} \geq 0$ and $\beta_{1} \geq 0$. To satisfy the stationary condition, $\alpha+\beta<1$.

2) The Power GARCH (PGARCH) Model-PGARCH $(1,1)$;

$$
\sigma_{t}^{\delta}=\alpha_{o}+\beta_{1} \sigma_{t-1}^{\delta}+\alpha_{1}\left(\left|\varepsilon_{t-1}\right|-\gamma_{1} \varepsilon_{t-1}\right)^{\delta}
$$

where, $\alpha_{o}$ is a constant, $\alpha_{1}$ and $\beta_{1}$ are the standard ARCH and GARCH parameters, $\gamma$ is the leverage parameter and $\delta$ is the parameter for the power term, and $\delta>0,\left|\gamma_{1}\right| \leq 1$. When $\delta=2$, the above equation becomes a classic GARCH model that allows for leverage effects and when $\delta=1$, the conditional standard deviation will be estimated. Also, the flexibility of the PGARCH model could be increased by considering $\delta$ as another coefficient that must be estimated.

\subsection{Mean Reversion}

Mean reversion means that current information has no influence on the long run forecast of the volatility. Persistence dynamics in volatility is generally captured in the GARCH coefficient(s) of a stationary GARCH-type model. In stationary GARCH-type models, the volatility mean reverts to its long run level, at a rate given by the sum of $\mathrm{ARCH}$ and $\mathrm{GARCH}$ coefficients, which is usually close to one (1) for financial time series. The average number of time periods for the volatility to revert to its long run level is measured by the half-life of the volatility shock. The mean reverting form of the basic GARCH $(1,1)$ model is given by;

$$
\left(\varepsilon_{t}^{2}-\bar{\sigma}^{2}\right)=\left(\alpha_{1}+\beta_{1}\right)\left(\varepsilon_{t-1}^{2}-\bar{\sigma}^{2}\right)+r_{t}+\beta_{1} r_{t-1}
$$

where $\bar{\sigma}^{2}=\frac{\alpha_{o}}{1-\alpha_{1}-\beta_{1}}$, the unconditional long run level of volatility and $r_{t}=\left(\varepsilon_{t}^{2}-\bar{\sigma}^{2}\right)$. The magnitude of the mean reverting rate $\alpha_{1}+\beta_{1}$ controls the speed of the mean reversion.

\subsection{Half-Life Measure of Volatility}

One measure of volatility persistence is the volatility half-life $\tau$, Engle and Patton (2001) defined half-life as the time required for the volatility to move half way back towards its unconditional mean. More precisely, $\tau$ is the smallest $k$ such that 


$$
\left|\sigma_{t+k \mid t}-\bar{\sigma}^{2}\right|=\frac{1}{2}\left|\sigma_{t+1 \mid t}-\bar{\sigma}^{2}\right|
$$

where $k$ is the number of days, $\sigma_{t+k \mid t}$ is the conditional expected value of volatility $k$ days into the future and $\bar{\sigma}^{2}$ is the unconditional long run level of volatility ( the mean level to which the unconditional variance eventually reverts).

Also, the GARCH $(1,1)$ process is mean reverting if $\left(\alpha_{1}+\beta_{1}\right)<1$, if this condition is satisfied, $\sigma_{t+k \mid t} \rightarrow \bar{\sigma}^{2}$ as $k \rightarrow \infty$. Thus, the forecast conditional variance reverts to the unconditional variance as the forecast horizon increases.

For $k \geq 2$ and a $\operatorname{GARCH}(1,1)$ process, the value of $\sigma_{t+k \mid t}$ is given by;

$$
\sigma_{t+k \mid t}=\bar{\sigma}^{2}+\left(\alpha_{1}+\beta_{1}\right)^{k-1}\left(\sigma_{t+1}-\bar{\sigma}^{2}\right), k \geq 2
$$

From Equation (6) and Equation (7), the number of days $k$ for a $\operatorname{GARCH}(1,1)$ process is given by;

$$
\left|\bar{\sigma}^{2}+\left(\alpha_{1}+\beta_{1}\right)^{k-1}\left(\sigma_{t+1}-\bar{\sigma}^{2}\right)-\bar{\sigma}^{2}\right|=\frac{1}{2}\left|\sigma_{t+1 \mid t}-\bar{\sigma}^{2}\right|
$$

Therefore, the half-life of a $\operatorname{GARCH}(1,1)$ process is given by;

$$
\tau=\frac{\log \left[\left(\alpha_{1}+\beta_{1}\right) / 2\right]}{\log \left(\alpha_{1}+\beta_{1}\right)}
$$

\section{Results and Discussion}

\subsection{Descriptive Statistics}

Table 1, shows the descriptive statistics of the returns of the three cryptocurrencies (Bitcoin, Litecoin and Ripple). All the three return series recorded positive mean return ranging from 0.0009 to 0.0011 with the highest mean return recorded in Ripple and the lowest mean return recorded in Litecoin. This indicates that, holders of the three cryptocurrencies made gains. The highest standard deviation was recorded in Ripple (0.0345) and the lowest was recorded in Bitcoin (0.0193). This indicates that, the level of risk associated with holding on to Ripple was higher compared with Bitcion and Litecoin. Two of the mean returns (Litecoin and Ripple) were positively skewed; an indication that, the upper tail of the distribution of the return series were ticker than the lower tail and that holders of Ripple and Litecoin had higher chances of making gains compared with Bitcoin. The three mean returns recorded kurtosis ranging from 11.1786 to 29.9421 meaning the three mean returns are leptokurtic thus, highly volatile.

Figures 1-3 show the plots of the returns in Bitcoin, Litecoin and Ripple

Table 1. Descriptive Statistics of Return Series

\begin{tabular}{ccccccc}
\hline Cryptocurrency & Mean & Max & Min & Std. Dev & Skewness & Kurtosis \\
\hline Bitcoin & 0.0010 & 0.1552 & -0.1156 & 0.0193 & -0.1381 & 11.1786 \\
Litecoin & 0.0009 & 0.3600 & -0.2223 & 0.0302 & 1.8005 & 28.2921 \\
Ripple & 0.0011 & 0.4462 & -0.2676 & 0.0345 & 2.0065 & 29.9421 \\
\hline
\end{tabular}

Source: Author's computation. 


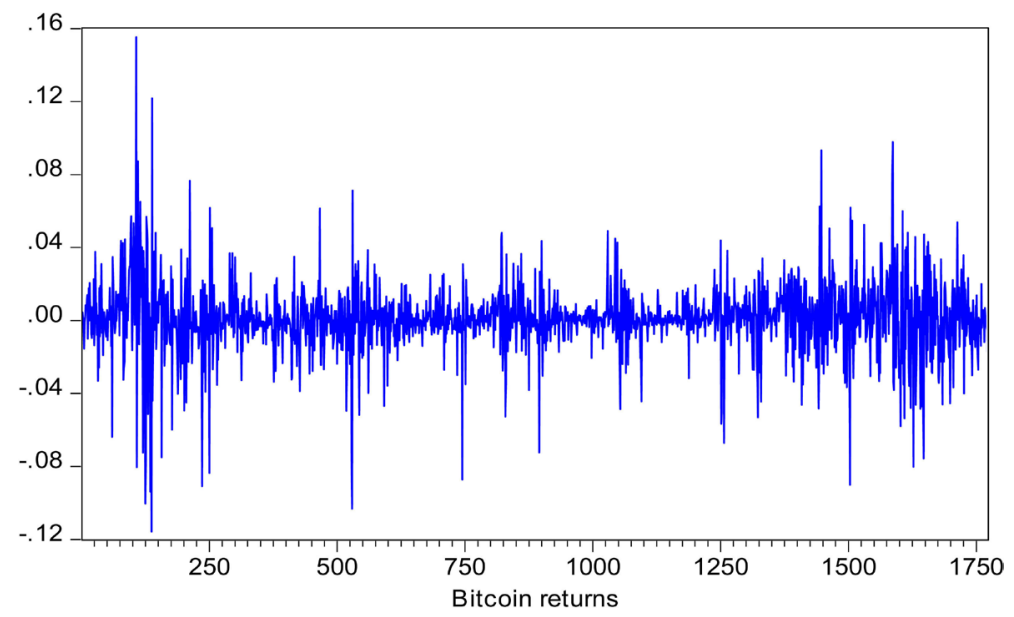

Source: Authors plot.

Figure 1. The plot of the daily Bitcoin returns Aug. 2013-Jun. 2018.

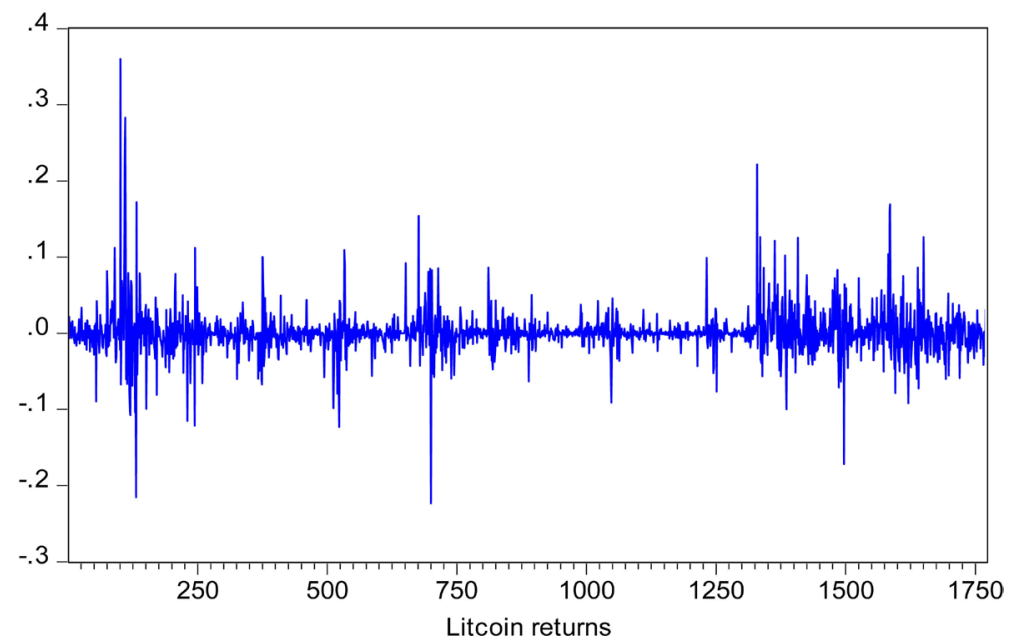

Source: Authors plot.

Figure 2. The plot of the daily Litecoin returns Aug. 2013-Jun. 2018.

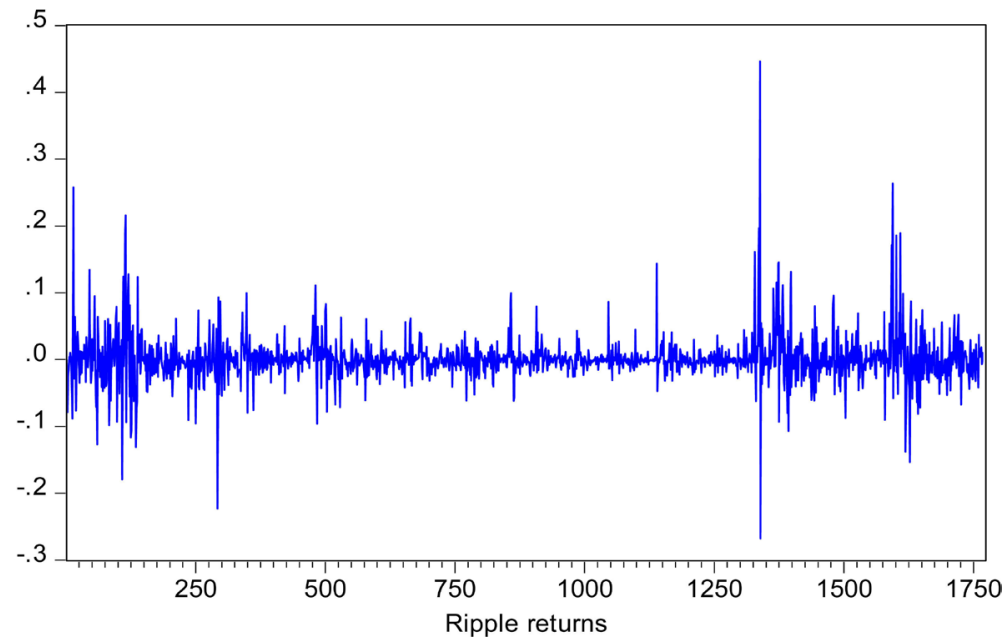

Source: Authors plot.

Figure 3. The plot of the daily Bitcoin returns Aug. 2013-Jun. 2018. 
respectively. It could be seen that, there is evidence of volatility clustering and long memory. That is, high returns tend to be followed by high returns and low returns followed by low returns. Also, the nature of volatility of the returns decays slowly.

\subsection{Further Analysis}

Table 2 shows the normality and autocorrelation test of the return series. It was realized that, the Jarque-Bera test for normality was significant at the $5 \%$ level of significance for the three return series meaning the return series were not normally distributed. The Ljung-Box Q-statistics for the return and squared returns show evidence of autocorrelation in both the return and squared return series since Q (30) and $\mathrm{Q}^{2}(30)$ were significant at the $5 \%$ level of significance.

To confirm that the returns series were not normally distributed, the Quantile-Quantile plot was employed. It is evidence from Figures 4-6 that the returns series were not normally distributed and exhibit the presence of outliers since

Table 2. Normality and Autocorrelation Test of the Return Series

\begin{tabular}{cccc}
\hline Cryptocurrency & Jarque-Bera & Q-Stats & $\mathrm{Q}^{2}$-Stats \\
\hline Bitcoin & $4947.0520^{* *}$ & $66.8360^{* *}$ & $687.0300^{* *}$ \\
& $(0.0000)$ & $(0.0000)$ & $(0.0000)$ \\
Litecoin & $48214.9800^{* *}$ & $49.6080^{* *}$ & $423.8000^{* *}$ \\
& $(0.0000)$ & $(0.0020)$ & $(0.0000)$ \\
Ripple & $54814.3000^{* *}$ & $47.0150^{* *}$ & $289.6400^{* *}$ \\
& $(0.0000)$ & $(0.0030)$ & $(0.0000)$ \\
\hline
\end{tabular}

Source: Author's computation; ${ }^{* *}$ significant at $5 \%$ level of significance.

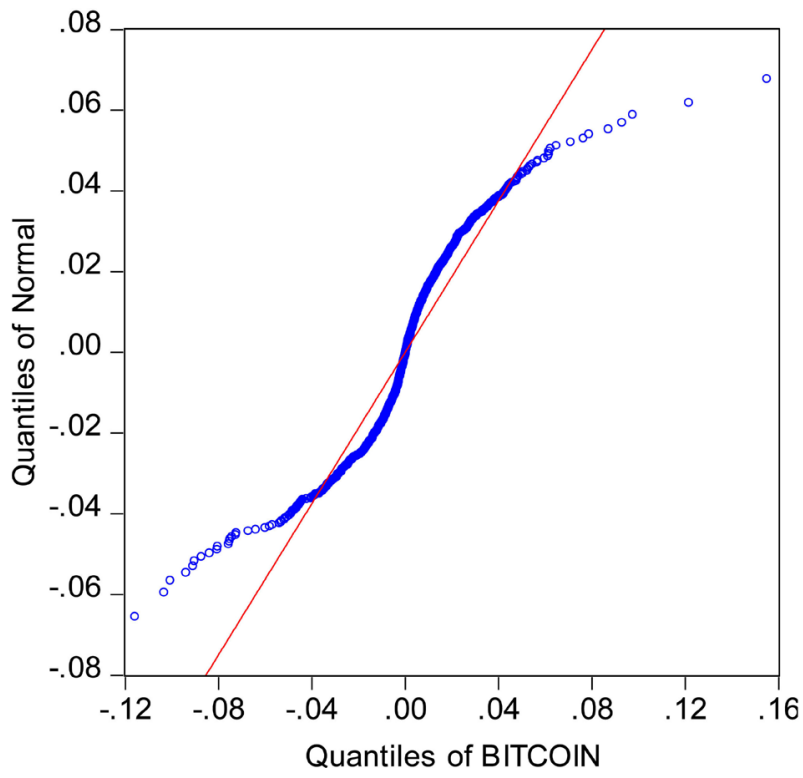

Source: Authors plot.

Figure 4. Normal Quantile-Quantile plot of Bitcoin daily returns Aug. 2013-Jun. 2018. 


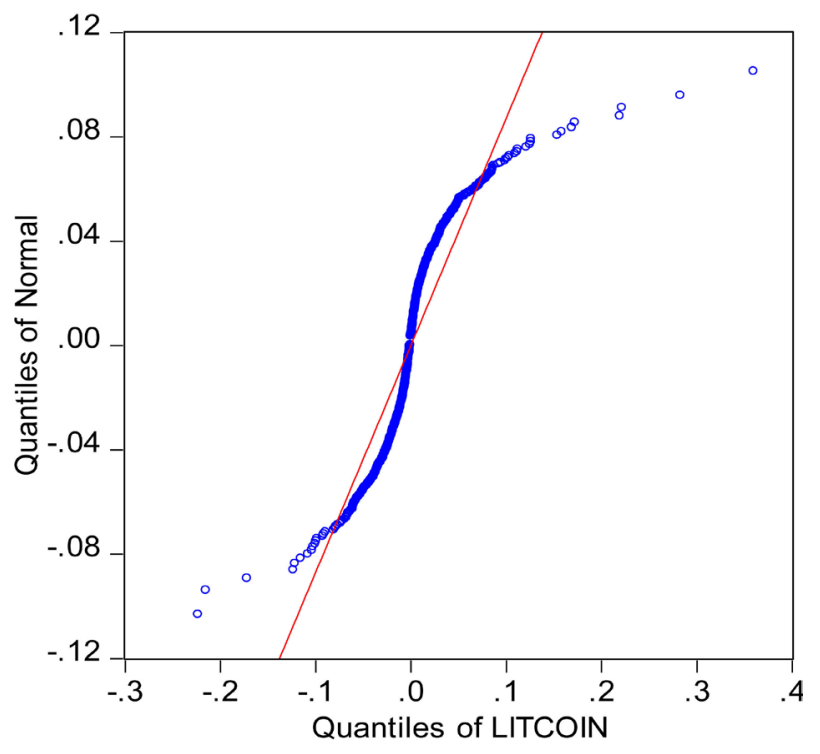

Source: Authors plot.

Figure 5. Normal Quantile-Quantile plot of Bitcoin daily returns Aug. 2013-Jun. 2018.

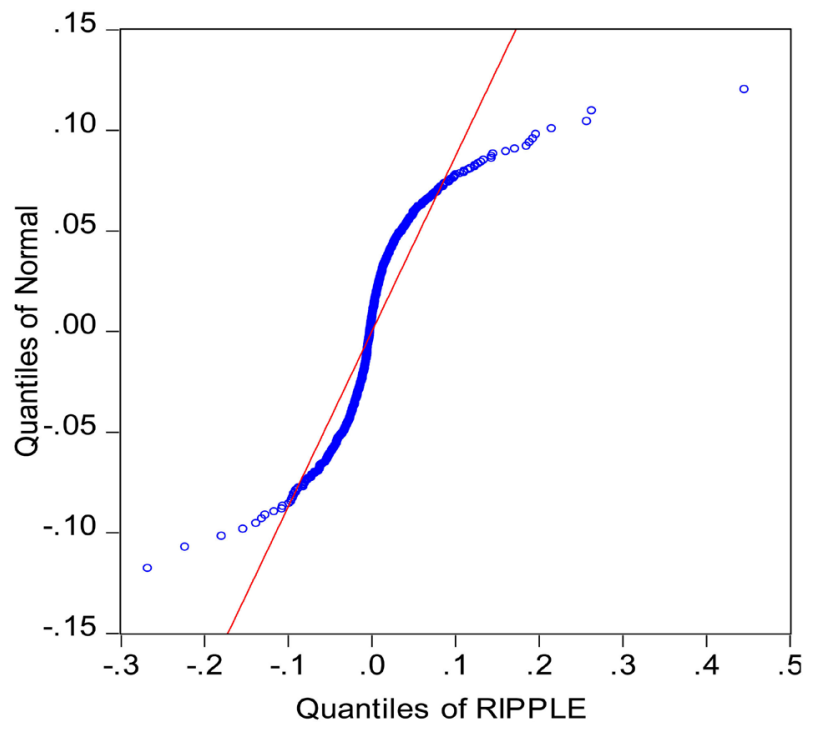

Source: Authors plot.

Figure 6. Normal Quantile-Quantile plot of Bitcoin daily returns Aug. 2013-Jun. 2018.

the points do not approximate the straight line.

In testing for stationarity, the $\mathrm{ADF}$ test was employed. It is evidence from $\mathrm{Ta}$ ble 3 that, the three returns series showed evidence of stationarity at the $5 \%$ level of significance.

In volatility modelling, it very paramount that one check for the presence of ARCH effects in the returns series. To examine the returns series for ARCH effects, the ARCH-LM test was employed. It is evidence from Table 4 that, all the three returns series exhibited $\mathrm{ARCH}$ effects at the $5 \%$ level of significance at lag 10, 20 and 30 since the $\mathrm{P}$-values are all less than 0.05 significance level.

It is always necessary to know the error distribution to use when performing 
volatility modelling. In achieving this, a pre-testing of the residuals of the three returns series was performed by fitting them to GARCH model under the three error distributions (Gaussian distribution, Student's-t distribution and Generalized Error Distribution (GED)). Table 5, reports on the AIC and BIC after fitting the residuals to a GARCH model. It was realized that, all the three returns

Table 3. ADF test of the return series.

\begin{tabular}{ccc}
\hline Cryptocurrency & Constant \& Trend Test Stats & P-value \\
\hline Bitcoin & $-41.8915^{\star *}$ & 0.0000 \\
Litecoin & $-40.9379^{\star *}$ & 0.0000 \\
Ripple & $-39.8768^{\star *}$ & 0.0000
\end{tabular}

Source: Author's computation; ${ }^{* *}$ significant at $5 \%$ level of significance.

Table 4. ARCH-LM test of the return series.

\begin{tabular}{cccc}
\hline Cryptocurrency & Lag & Test Stats & P-value \\
\hline Bitcoin & 10 & $257.1072^{* *}$ & 0.0000 \\
& 20 & $292.9360^{* *}$ & 0.0000 \\
& 30 & $340.7687^{* *}$ & 0.0000 \\
Litecoin & 10 & $220.3011^{* *}$ & 0.0000 \\
& 20 & $247.6758^{* *}$ & 0.0000 \\
Ripple & 30 & $281.9466^{* *}$ & 0.0000 \\
& 10 & $195.3764^{* *}$ & 0.0000 \\
& 20 & $221.2548^{* *}$ & 0.0000 \\
& 30 & $224.1679^{* *}$ & 0.0000 \\
\hline
\end{tabular}

Source: Author's computation; ${ }^{* *}$ significant at $5 \%$ level of significance.

Table 5. Residual analysis of GARCH effect.

\begin{tabular}{ccc}
\hline Cryptocurrency & AIC & BIC \\
\hline$\underline{\text { Bitcoin }}$ & & -5.3971 \\
Gaussian Distribution & -5.4064 & -5.6782 \\
Student's-t Distribution & -5.6905 & -5.6752 \\
GED & -5.6875 & \\
Litecoin & & -4.5399 \\
Gaussian Distribution & -4.5492 & -5.1937 \\
Student's-t Distribution & -5.2061 & -5.1396 \\
GED & -5.1520 & \\
Ripple & & -4.4695 \\
Gaussian Distribution & -4.4788 & -4.8465 \\
Student's-t Distribution & -4.8589 & -4.8270 \\
GED & -4.8393 & \\
\hline
\end{tabular}

Source: Author's computation. 
series had Student's-t distribution selected by the AIC and BIC since both recorded the least information criteria values. Therefore, it was concluded that in fitting the returns series to any univariate GARCH model, it will be prudent to fit the GARCH model under the Student's-t distribution. Therefore, this result is also in line with Salisu et al. (2018) who used the pretesting of residual in selecting the appropriate error distribution.

A symmetric univariate GARCH model was employed to handle the magnitude of the returns. From Table 6, it is evidence that all the returns series were not stationary since their summation of $\alpha$ and $\beta$ are all greater than one, meaning volatility in these returns series using $\operatorname{GARCH}(1,1)$ model is an explosive process and that, volatility will not mean revert. Nevertheless, even though the model exhibited non-stationarity, the ACRH-LM test was not significant for all the returns series meaning further conditional heteroscedasticity was remove from the returns series.

Since the GARCH $(1,1)$ exhibited non-stationarity, there was the need to employ another volatility model. Hence, an asymmetric volatility model; PGARCH was considered.

An asymmetric GARCH model was employed to model the magnitude and sign of volatility in the returns series and also since the symmetric GARCH model was not stationary for all the returns series. From Table 7, it could be seen that, the PGARCH $(1,1)$ was stationary for all the three returns series since

Table 6. Estimated GARCH model with student's-t distribution.

\begin{tabular}{cccc}
\hline Cryptocurrency & $\alpha$ & $\beta$ & ARCH-LM \\
\hline Bitcoin & $0.3672^{* *}$ & $0.8179^{* *}$ & 0.0545 \\
& $(0.0000)$ & $(0.0000)$ & $(0.8155)$ \\
Litecoin & 1.9511 & $0.8460^{* *}$ & 0.1005 \\
& $(0.6458)$ & $(0.0000)$ & $(0.7512)$ \\
Ripple & $1.0579^{* *}$ & $0.6403^{* *}$ & 0.1277 \\
& $(0.0218)$ & $(0.0000)$ & $(0.7208)$ \\
\hline
\end{tabular}

Source: Author's computation; ${ }^{* *}$ significant at $5 \%$ level of significance.

Table 7. Estimated PGARCH model with student's-t distribution.

\begin{tabular}{cccccc}
\hline Cryptocurrency & $\alpha$ & $\beta$ & $\gamma$ & $\delta$ & ARCH-LM \\
\hline Bitcoin & $0.2511^{\star *}$ & 0.4730 & $0.8492^{\star *}$ & $0.9721^{\star *}$ & 0.2035 \\
& $(0.0000)$ & 0.4385 & $(0.0000)$ & $(0.0000)$ & $(0.6519)$ \\
Litecoin & $0.4738^{* *}$ & 0.3868 & $0.8580^{* *}$ & $1.0137^{\star *}$ & 0.0732 \\
& $(0.0152)$ & $(0.1632)$ & $(0.0000)$ & $(0.0000)$ & $(0.7867)$ \\
Ripple & $0.5245^{\star *}$ & 0.2851 & $0.6882^{* *}$ & $0.8900^{* *}$ & 0.0531 \\
& $(0.0000)$ & $(0.1654)$ & $(0.0000)$ & $(0.0000)$ & $(0.8177)$ \\
\hline
\end{tabular}

Source: Author's computation; ${ }^{* *}$ significant at $5 \%$ level of significance. 
they all exhibited their ARCH and GARCH components to be less one. Also, the parameter $\gamma$ which measures leverage effect was significant and positive for the three returns series. This means that, positive shocks are associated with higher volatility than negative shocks of the same magnitude. The ARCH-LM test shows that there are no further ARCH effect meaning the variance equations are well specified for all the three returns series. Again, since the Power GARCH (1, 1) exhibited stationarity for the three returns series, it was used for the half-life measure volatility in the three returns series.

Figures 7-9 show the PGARCH $(1,1)$ conditional variance plots of the Bitcoin, Litecoin and Ripple returns respectively. It is evidence that, they all exhibit

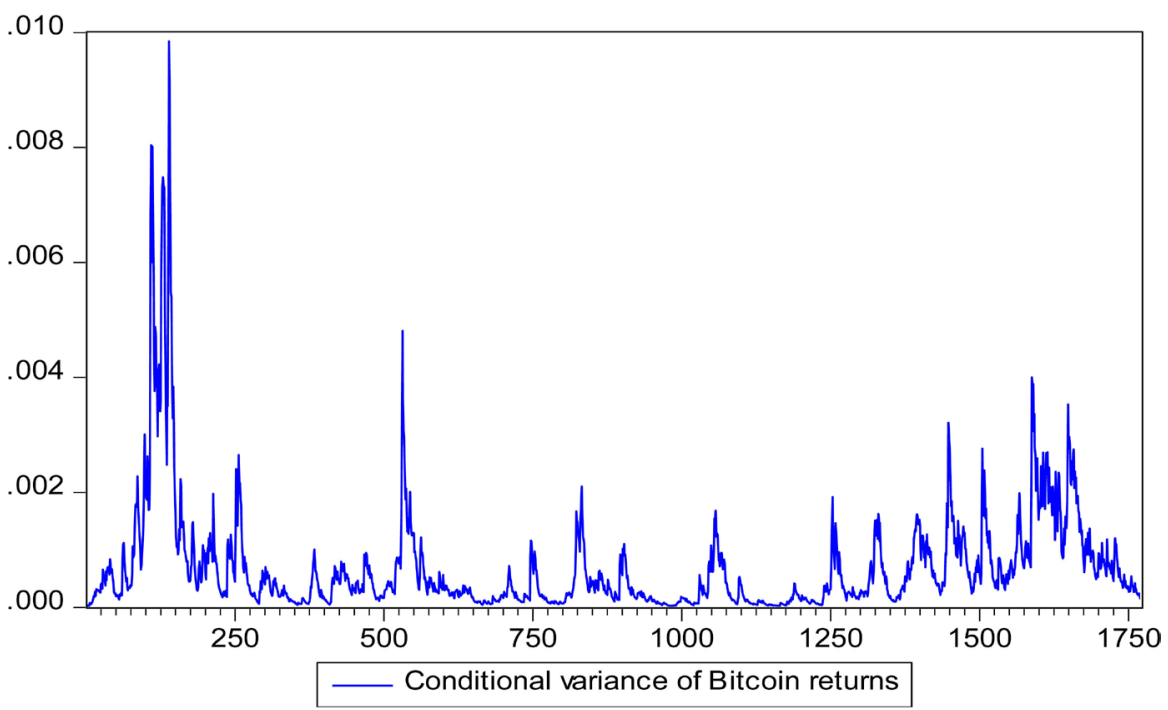

Source: Authors plot.

Figure 7. PGARCH $(1,1)$ plot of Bitcoin.

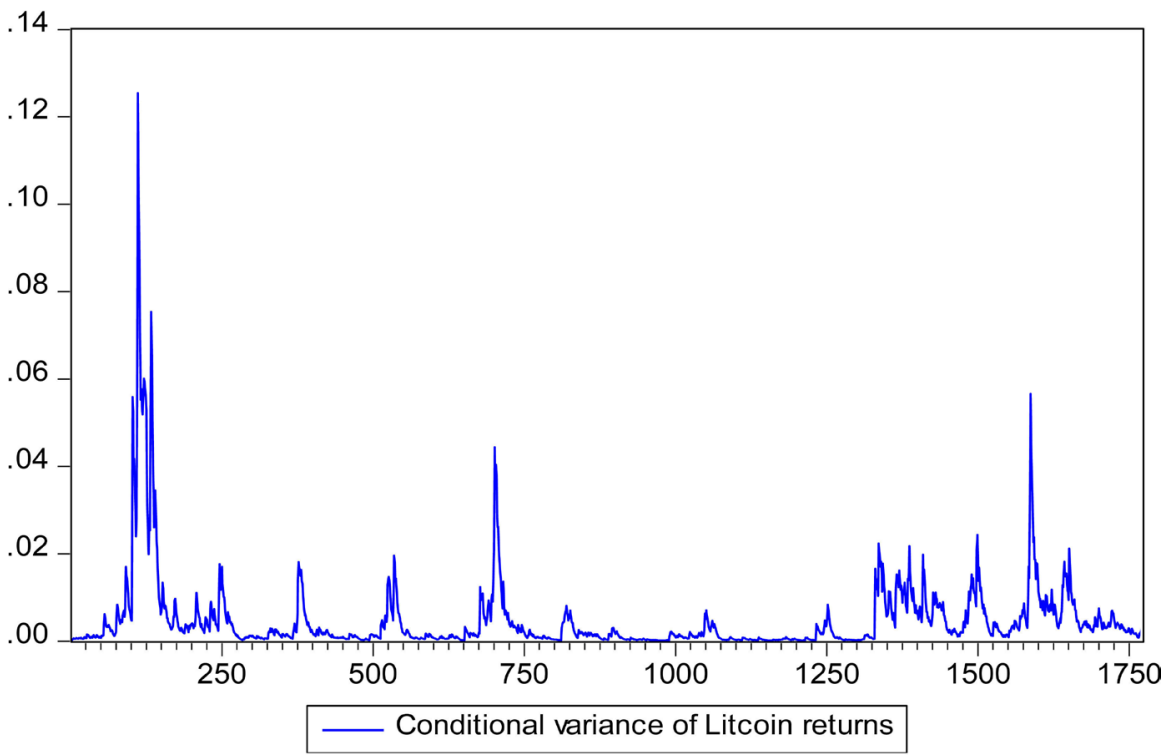

Source: Authors plot.

Figure 8. PGARCH $(1,1)$ plot of Litecoin. 


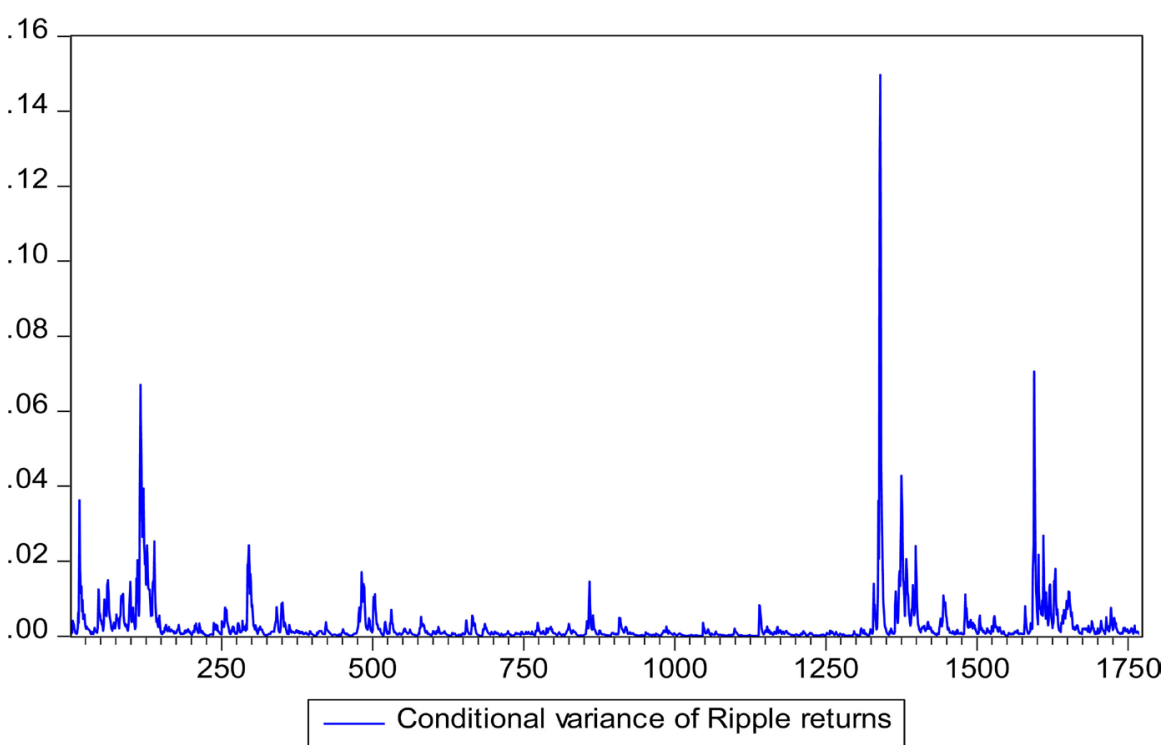

Source: Authors plot.

Figure 9. PGARCH $(1,1)$ plot of Ripple.

Table 8. Half-life measure of the returns series.

\begin{tabular}{ccc}
\hline Cryptocurrency & $\alpha+\beta$ & Half-life (days) \\
\hline Bitcoin & 0.7241 & 3 \\
Litecoin & 0.8606 & 6 \\
Ripple & 0.8096 & 4 \\
\hline
\end{tabular}

Source: Author's computation.

some systematic trends in them with Bitcoin exhibiting much systematic trend followed by Litecoin and then Ripple.

The PGARCH $(1,1)$ model was employed to investigate the half-life volatility measure of the returns series. From Table 8 it is evidence that, all the three returns series exhibited volatility persistence and long memory since all the three return series had their ARCH and GARCH components less 1. The half-life of Bitcoin, Litecoin and Ripple were 3 days, 6 days and 4 days respectively. This means that, they all have strong mean reverting rate and short half-life. Again, a shock in Bitcoin will take 3 days for it to return half way back to its volatility. A shock in the returns of Litecoin will take 6 days for it to mean revert without any further volatility. Volatility in Ripple will last for 4 days after which it will return half way back to its mean without further volatility. For investors on the coin market, it will be prudent to stay with coins with strong mean reversion and thus short half-life so as not to suffer much volatility with your portfolios. Therefore, in this paper, it advisable to stay with Bitcoin since it has the strongest mean reversion rate and the shortest half-life, followed by Ripple and then Litecoin.

\section{Conclusion}

This paper determined the half-life volatility measure of three cryptocurrencies 
(Bitcoin, Litecoin and Ripple). In choosing the appropriate error distribution for the volatility modelling, a pre-testing of the residuals was done in which the student's-t distribution was selected. A symmetric GARCH $(1,1)$ model was employed but it was realized that; it was non-stationary for all the returns series. Therefore another GARCH-family model was employed; the PGARCH $(1,1)$ which exhibited stationarity in all the three returns series. The PGARCH $(1,1)$ was then considered in determining the half-life of the three returns series. The results revealed that, the half-life was 3 days, 6 days and 4 days for Bitcoin, Litecoin and Ripple respectively. This shows that, the three coins had strong mean reversion and short half-life. It is therefore prudent for investors to stay with Bitcoin since it has the shortest half-life.

This research did not allow for the selection of GARCH order but rather used the basic GARCH $(1,1)$ for the analysis. Further research can have a look at allowing for a suitable GARCH order aside the basic $\operatorname{GARCH}(1,1)$.

\section{Conflicts of Interest}

The authors declare no conflicts of interest regarding the publication of this paper.

\section{References}

Ali, R., Barrdear, J., Clews, R., \& Southgate, J. (2014). The Economics of Digital Currencies. Bank of England Quarterly Bulletin, 54, 276-286.

Al-Khazali, O., Bouri, E., \& Roubaud, D. (2018). The Impact of Positive and Negative Macroeconomic News Surprises: Gold versus Bitcoin. Economics Bulletin, 38, 373-382.

Balcilar, M., Bouri, E., Gupta, R., \& Roubaud, D. (2017). Can Volume Predict Bitcoin Returns and Volatility? A Quantiles-Based Approach. Economic Modelling, 64, 74-81. https://doi.org/10.1016/j.econmod.2017.03.019

Baur, D. G., Kihoon, H., \& Andrian. D. L. (2017). Bitcoin: Medium of Exchange or Speculative Assets?

Bouri, E., Azzi, G., \& Haubo Dyhrberg, A. (2017). On the Return-Volatility Relationship in the Bitcoin Market around the Price Cash of 2013. Economics, 11, 1-16.

Bradbury, D. (2013). The Problem with Bitcoin. Computer Fraud \& Security, 2013, 5-8. https://doi.org/10.1016/S1361-3723(13)70101-5

Cheah, E.-T., Mishraa, T., Parhi, M., \& Zhang, Z. (2018). Long Memory Interdependency and Inefficiency in Bitcoin Markets. Economics Letters, 167, 18-25. https://doi.org/10.1016/j.econlet.2018.02.010

Conrad, C., \& Kleen, O. (2018). Two Are Better Than One: Volatility Forecasting Using Multiplicative Component GARCH Models. Journal of Risk and Financial Management, 23, 1-51.

Dehrberg, A. H. (2016). Bitcoin, Gold and the Dollar-A GARCH Volatility Analysis. Finance Research Letters, 16, 85-92. https://doi.org/10.1016/j.frl.2015.10.008

Engle, R. F., \& Patton, A. J. (2001). What Good Is a Volatility Model? Quantitative Finance, 1, 237-245. https://doi.org/10.1088/1469-7688/1/2/305

Katsiampa, P. (2017). Volatility Estimation for Bitcoin: A Comparison of GARCH Models. Economics Letters, 158, 3-6. https://doi.org/10.1016/j.econlet.2017.06.023 
Khuntia, S., \& Paltanayak, J. K. (2018). Adaptive Market Hypothesis and Evolving Predictability of Bitcoin. Economics Letters, 167, 26-28.

https://doi.org/10.1016/j.econlet.2018.03.005

Koutmos, D. (2018). Bitcoin Returns and Transaction Activity. Economics Letters, 167, 81-85. https://doi.org/10.1016/j.econlet.2018.03.021

Kristoufek, L. (2015). What Are the Main Drivers of the Bitcoin Price? Evidence from Wavelet Coherence Analysis. PLoS ONE, 10, e0123923.

https://doi.org/10.1371/journal.pone.0123923

Li, X., \& Wang, C. A. (2017). The Technology and Economic Determinants of Cryptocurrency Exchange Rates. The Case of Bitcoin. Decision Support Systems, 95, 49-60. https://doi.org/10.1016/j.dss.2016.12.001

Polasik, M., Piotrowska, A. I., Wisniewski, T. P., Kotkowski, R., \& Lightfoot, G. (2015). Price Fluctuations and the Use of Bitcoin: An Empirical Inquiry. International Journal of Electronic Commerce, 20, 9-49. https://doi.org/10.1080/10864415.2016.1061413

Salisu, A. A., Tiwari A. K., \& Raheem I. D. (2018). Analysing the Distribution Properties of Bitcoin Returns. Working Papers Series, CWPS 0058, Ibadan: Centre for Econometric and Allied Research, University of Ibadan. 